Copyright: Medicine, Health Care and Philosophy

Article can be accessed at: http://link.springer.com/article/10.1007\%2Fs11019-010-9273-0.

\title{
Can Curative or Life-Sustaining Treatment Be WithHeld OR WITHDRAWN? \\ The OPINIONS AND VIEWS OF INDIAN PALLIATIVE-CARE NURSES AND PhySiCians
}

Joris Gielen, Sushma Bhatnagar, Seema Mishra, Arvind K. Chaturvedi, Harmala Gupta, Ambika Rajvanshi, Stef Van den Branden, Bert Broeckaert

\section{Introduction}

With modern medical therapies life can often be significantly prolonged. Yet, sometimes in cases of severe illness and advanced disease a patient and his or her caregivers may be confronted with the question whether curative or life-sustaining treatment is still worthwhile. They may be of the opinion that the proposed treatment will not have the desired outcome or the side-effects of the treatment will outweigh the benefits. Patients and caregivers will have to decide whether they will initiate or withhold, continue or withdraw the treatment. Even if the caregivers want to administer the treatment, the patient may still refuse the therapy. Therefore, Broeckaert distinguishes between three main types of treatment decisions regarding curative or life-sustaining treatment in advanced disease: (1) initiating or continuing a curative or life-sustaining treatment, (2) a non-treatment decision, and (3) refusal of treatment. Curative or life-sustaining treatments include all treatments through which the treating physician intends to cure or stabilise the illness, and/or prolong or sustain the patient's life. Broeckaert describes a non-treatment decision as a decision to withdraw or withhold a curative or life-sustaining treatment, because in the given situation this treatment is deemed to be no longer meaningful or effective. In the case of refusal of treatment a curative 
or life-sustaining treatment is withdrawn or withheld because the patient refuses this treatment (Broeckaert and Flemish Palliative Care Federation, 2006; Broeckaert, 2008; Broeckaert, 2009a; Broeckaert, 2009b).

Several studies in Western countries have attempted to measure the incidence of nontreatment decisions. A comparative study in six European countries in 2001-2002 showed that potentially life-prolonging treatment had been withheld or withdrawn in $27 \%$ of all deaths in Belgium, in $23 \%$ of all deaths in Denmark, in $6 \%$ of all deaths in Italy, in $30 \%$ of all deaths in the Netherlands, in $22 \%$ of all deaths in Sweden, and in $41 \%$ of all deaths in Switzerland (Bosshard et al., 2005). Other studies found that potentially life-prolonging treatment had been withheld or withdrawn in $28.6 \%$ of all deaths in Australia (Kuhse et al., 1997) and in at least $30.3 \%$ of all of all deaths in the UK (Seale, 2006).

There are no data from which we can derive the frequency of withholding or withdrawal of curative or life-sustaining treatment in Indian health care in general. Kapadia et $a l$. studied the frequency of limitation and withdrawal of intensive therapy at the end of life in four ICU's in Mumbai. They observed that therapy was limited in 34\% of all studied deaths in the ICU's. $25 \%$ of the patients who died with limited therapy were not intubated terminally. $67 \%$ were initially intubated and ventilated but further escalation of therapy was subsequently withheld. Therapy was withdrawn in $8 \%$ of the studied ICU deaths (Kapadia et al., 2005).

In India, there is no law directly regulating withholding and withdrawal of treatment. Generally, the right of an individual to refuse treatment that only affects him or herself and his or her family members is not disputed. The right to refuse treatment can be seen in article 21 of the Indian Constitution, which promulgates the right to personal liberty. Yet, it has remained unclear to what extent article 21 can be applied to the refusal of curative or lifesustaining treatments once the treatment has been started, since in that case refusal of curative or life-sustaining treatment could be interpreted as suicide, which is illegal in India. Indian 
law also does not clarify whether curative or life-sustaining treatment can be withheld or withdrawn in patients who are incapable of deciding or communicating about treatment decisions. Since the legality of withholding or withdrawing curative or life-sustaining treatment in terminal patients can be disputed, physicians who withhold or withdraw curative or life-sustaining treatment in such patients may be liable to litigation. Physicians could, for instance, be accused of abetting suicide. Understandably, physicians in India may be less inclined to withdraw or withhold curative or life-sustaining treatment, even if the treatment seems futile to them (Balakrishnan and Mani, 2005; Kapadia et al., 2005).

In India, decisions regarding forgoing of curative or life-sustaining treatment are further complicated by the Indian socio-economical context and the organisation of health care. Health care in India is provided by the government, private enterprise and non-profit organisations. Since health insurance is uncommon in India and costs of medical treatment can accumulate quickly extensive treatment at good private health-care institutions is not a viable option for the majority of the Indian population. Health care provided by the government or non-profit organisations is generally inexpensive, although the availability of this type of health care is largely insufficient to cater to the needs of the poor and the lessaffluent (World Health Organisation Country Office for India, 2006). Consequently, in the Indian setting financial considerations may play an important role when decisions regarding forgoing curative or life-sustaining treatment are taken, since a decision to initiate or continue such treatment may financially ruin a family.

Obviously, the issue of forgoing curative or life-sustaining treatment is of prime importance to Indian palliative care. A decision to start, forgo, continue or withdraw a curative or life-sustaining treatment can have a huge impact on the symptoms which the palliative-care team has to control. Moreover, since the palliative-care physicians and nurses provide holistic care, they may have a close relationship with the patient and his or her 
relatives, who may have come to value and appreciate the views and understanding of the palliative-care physicians and nurses. In this way, the patients and their families may turn to the palliative-care physicians and nurses for advice whenever a decision regarding withholding or withdrawal of curative or life-sustaining treatment has to be taken.

Palliative care was introduced in India in the second half of the 1980's. Since then, in different parts of India palliative-care programmes have been developed, although coverage of palliative care in India still remains a huge problem. Most of these programmes focus on cancer patients (Rajagopal and Palat, 2002; Shanmugasundaram et al., 2006; International Observatory on End of Life Care, 2007; McDermott et al., 2008). In India, palliative care is mainly provided at home by professional palliative-care teams and trained volunteers, and in hospices, pain clinics and palliative-care units in hospitals (Seamark et al., 2000; Shanmugasundaram et al., 2006; International Observatory on End of Life Care, 2007; McDermott et al., 2008). Organisations providing palliative care in India rely on various sources of funding and generally the charges made to patients for palliative care are limited.

So far the attitudes of Indian palliative-care physicians and nurses to the withholding and withdrawal of curative or life-sustaining treatment in advanced disease have not been studied. With this study we wanted to chart the attitudes of Indian palliative-care nurses towards these issues. We also wanted to know when and why the nurses and physicians consider withholding and withdrawal of curative or life-sustaining treatment acceptable or unacceptable in advanced disease. Since palliative care will often imply forgoing burdensome or futile curative or life-sustaining treatments, a study on the attitudes of Indian palliative-care physicians and nurses to these issues will provide insight into how these physicians and nurses perceive their own work and care, and how in their view they are or could be involved in the decision-making process regarding forgoing curative or life-sustaining treatments. 


\section{Method}

The attitudes of Indian palliative-care physicians and nurses towards withholding and withdrawal of curative or life-sustaining treatment in advanced disease can be complex and diverse. Argumentations regarding the acceptability of these treatment decisions are hard to be adequately represented in quantitative surveys. Therefore, an explorative qualitative research design was required to gain insight into these attitudes. We opted for face-to-face interviews following Grounded-Theory methodology (Glaser and Strauss, 1974; Strauss and Corbin, 1998) using a semi-structured questionnaire.

\section{Recruitment of Participants}

To gain access to eligible participants, we contacted the directors of four institutions and organisations that provide palliative care (hospice, home-care, pain clinic, palliative-care unit) in New Delhi, and explained them the aims and methodology of the research project. The directors of all contacted institutions and organisations were willing to support the research project and granted permission to interview physicians and nurses working in the palliativecare programmes. In two institutions, there was an ethics committee, and approval of the research project by these committees was required before any physician or nurse working in these institutions could be interviewed. The directors of the palliative-care programmes in these institutions obtained the approval of the respective ethics committees. The directors of the palliative-care programmes provided a list with the names of physicians and nurses in their institutions or organisations who had been working in Indian palliative care since at least five months, and who were fluent in either Hindi or English. The number of interviewees was not fixed in advance, but depended on when theoretical saturation would be reached. 
Theoretical saturation occurs when further data collection and analysis would not yield new aspects or insights. Theoretical saturation was reached after 27 interviews.

Seventeen participants were female and 10 were male. The average age of the interviewees was 42.7 years (std. dev. 11.09). Nine participants were born in Kerala, 5 in Uttar Pradesh, 3 in Haryana, 2 in Assam, 2 in New Delhi, 1 in Tamil Nadu, 1 in Rajasthan, 1 in Punjab, 1 in Maharashtra, 1 in Uttarakhand, and 1 in Madhya Pradesh. Eleven participants were working in palliative home care, 4 in a hospice, 3 in a palliative-care unit in a hospital, 2 in a pain clinic, and 7 in a pain clinic and a palliative-care unit. Eight participants were Christian, and 19 were Hindu. All participants were fluent in either Hindi, English or both.

\section{Content of the Interviews}

The semi-structured questionnaire which was used during the interviews covered demographic information about the participants, and several issues related to palliative care, ethical attitudes, and world view. As part of the inquiry after the participants' ethical attitudes, the interviewees were offered three hypothetical cases dealing with forgoing or administering curative or life-sustaining treatment in advanced disease. Through these three cases, which were each followed by a focused question, we solicited the interviewees' opinions on initiation or continuation of curative or life-sustaining treatment, non-treatment decisions, and refusal of treatment in advanced disease. Each of these three cases corresponds to one of the three types of treatment decisions regarding curative or life-sustaining treatment in advanced disease as described by Broeckaert (Broeckaert and Flemish Palliative Care Federation, 2006; Broeckaert, 2008; Broeckaert, 2009a). The cases are mentioned in the box below.

\section{Case 1 (initiating or continuing a curative or life-sustaining treatment)}

There exists a cancer treatment that may prolong life with a few weeks. This treatment has 
many negative side-effects. Should a physician opt for this treatment?

\section{Case 2 (non-treatment decision)}

An unconscious patient is artificially kept alive (ventilator, artificial nutrition and/or hydration). The patient is in an irreversible coma. Should the devices be switched off so that the patient dies? Who should decide about that?

\section{Case 3 (refusal of treatment)}

A physician has told his patient that chemotherapy may cure his cancer. The patient has the financial means to afford this treatment. Has the patient the right to refuse this treatment, even if he knows he will die soon if no treatment is administered?

The order of the questions and cases in the interviews was not fixed. As much as possible questions were asked and cases presented in relation to what the interviewee had said. Answers of the interviewees to questions or cases triggered new questions which were sometimes also asked in subsequent interviews to obtain a clearer picture of the opinions and attitudes of Indian palliative-care physicians and nurses.

\section{Data Collection}

14 physicians and 13 nurses were interviewed from May to September 2008. The interviews were conducted at a quiet location at the interviewee's workplace. Before the formal start of the interview, the interviewer (Joris Gielen) explained the general aim of the interview and the research project to the interviewee. The interviewer promised the interviewee that only the interviewer would have full access to the non-anonymous data, and that the names of the participants would not be mentioned in any reports about the study. Since physicians and 
nurses working in palliative care in New Delhi come from different parts of India, the interviewees were informed they could express their ideas and opinions in either Hindi or English, the two languages that are most common in New Delhi and are also understood and spoken by the interviewer. The interviewer also asked permission to record the interview as this would allow him to transcribe the interview word by word, which would, in turn, enhance the reliability of the collected data. Two respondents (one physician and one nurse) said they did not feel comfortable with the idea that the interview would be recorded. In these cases, the interview was not recorded and the interviewer made extensive written notes which were typed out and completed by the interviewer shortly after the interview. All other interviews were recorded. On average each interview took 50 minutes.

\section{Analysis}

Data collection and analysis progressed simultaneously. Every recorded interview was transcribed verbatim by the interviewer. The data were analysed by the interviewer following Glaser and Strauss' approach of Grounded Theory. Key concepts were identified in the interviews. Codes were added to the data. Through constant comparisons categories were determined and associations between categories were clarified. For the data analysis MAXQDA 2007 was used. The reliability of the data and analysis was enhanced by applying theoretical sampling and including evaluative feedback from the research supervisors. Theoretical sampling implies that researchers strive for a sample that is as heterogeneous as possible in order to maximize the possibility of discovering new data that could elucidate the evolving theory. While the data collection and analysis were in progress, regularly the outcomes of the research were discussed with the supervisors. The supervisors commented on the results and offered suggestions for the analysis and interpretation of the data. 
To protect the anonymity of the participants, their names have not been mentioned in the text and after the quotes in the results section. The name of each respondent has been replaced by a number. Each number has been assigned to one particular participant.

\section{Results}

In the course of the interviews, the three hypothetical cases were presented to the participants. In all three cases, the physicians and nurses tended to find forgoing treatment an ethically acceptable option. In the case of the initiating of treatment and the case of the non-treatment decision, forgoing the treatment was generally even the preferred decision. Nevertheless, the participants were aware of the ethical complexity of the cases, and of contextual arguments which have to be taken into consideration. The participants found it important to look at the broader context in which concrete treatment decisions are taken. The answers of the interviewees indicated they realised that in this kind of cases an easy fully satisfactory solution is often not at hand. In general, the palliative-care physicians and nurses were of the opinion that they could play an important advisory role in the decision-making process.

\section{Attitudes to Initiating Curative or Life-sustaining Treatment}

The interviewees were asked whether a physician should opt for a treatment which may prolong a terminal cancer patient's life with a few weeks, but has many negative side-effects. The physicians and nurses agreed that such a cancer treatment should preferably not be administered, although they added there can be circumstances in which administering such treatment may be acceptable. Given this contextual complexity the participants mainly argued they cannot decide for the patients. The interviewees considered it their task to provide all essential information to the patients and their relatives to enable them to take an informed decision. 
According to the participants, most often a patient does not benefit from a treatment as described in the case, because - as one of the home-care physicians (19) said - "the treatment should not be worse than the illness". The interviewees were of the opinion that brief extension of life at the expense of quality of life is not worthwhile.

It seems to me that the life that lies ahead of him will be full of suffering. There'll be a lot of severe side-effects. So according to me he will not be in a good condition. The quality of life would not be very good. So I think it is not advisable to go for such kind of treatment. (7: physician working in pain clinic and palliative-care unit)

The patient will suffer a lot. And his quality of life will deteriorate. So even if he adds days to his life, still this life has no meaning because the patient is suffering so much. (25: hospice physician)

The patient does not benefit from such treatment in any way. That's why we don't give that treatment. There is no harm in not giving the treatment to him. (21: home-care nurse)

The interviewees did not consider the few days or weeks which can be added to the life of a cancer patient who is in severe pain a real benefit. A physician and a nurse even wondered whether cancer treatment aimed at prolonging the life of a terminal patient who is going through immense suffering can really extend this patient's life span. They said to know from their experience that sometimes patients even die faster due to this kind of treatment.

I've seen that some patients have more problems if they go for treatment. And they die because of those problems. I've seen this. It is my own experience. I've seen many patients who got that chemotherapy done or got the surgery done. And because of that they had problems. (3: home-care physician)

The interviewees were convinced that they will only invite more suffering by administering the life-prolonging treatment to the cancer patient in the hypothetical case.

If you prolong life and he has pain you will invite more suffering only. (6: physician working in a pain clinic) 
First, he is suffering due to the cancer. Because of the disease he is suffering a lot. And there will be many side-effects, although his life is prolonged with just a few weeks. We're just increasing his suffering. (7: physician working in pain clinic and palliativecare unit)

You shouldn't administer such treatment. ... The patient's condition will be made worse. So that shouldn't be done. (10: home-care nurse)

For the interviewees, palliative treatment was the preferred therapy in such a case. In the interviews, the physicians and nurses enumerated many therapies which can be administered to control pain and symptoms. They argued that in the terminal stage of a disease like cancer the symptoms should be controlled in the first place, rather than attempting to prolong life at all cost.

You should get the maximum care. At least he should be relieved of the pain. (6: physician working in pain clinic)

I would prefer a palliation of those symptoms. I would like to give a patient a symptom free life span, whatsoever is remaining. (8: physician working in pain clinic and palliative-care unit)

I am fully convinced that that patient should go for palliative care, and not for radiation or any cancer treatment. (22: hospice nurse)

Although the interviewees favoured palliative treatment for a suffering cancer patient with very limited life expectancy, and would prefer to forgo curative or life-sustaining treatment, many participants referred to contextual elements which have to be taken into consideration while deciding about withholding curative or life-sustaining treatment. The physicians and nurses tended to find it difficult to formulate an absolute rule regarding withholding curative or life-sustaining treatment. Several contextual elements which can play a role in the decision-making process were mentioned in the interviews. 
One home-care physician mentioned that a patient's age can be an important criterion while deciding about the administration of curative or life-sustaining treatment.

I've seen that sometimes when the patient is young, the relatives want that something is done. They want the treatment, whatever the cost may be. They want life to be sustained. If the patient is very old, for instance in his sixties or seventies, then they don't want. It depends on the patient's age. (3: home-care physician)

Furthermore, the patient's physical condition and life expectancy were seen by the interviewees as aspects which can influence decisions about the administration of curative or life-sustaining treatment.

It also depends on the patient's general condition and age, for instance, if a patient is young and does not have metastases. (3: home-care physician)

Whenever the life-expectancy is more than six months active intervention should be done. ... It should be done, even if there are few side effects, or many. ... If the lifeexpectancy is less than six months then one should think. If the side-effects are very serious, if they will cause a lot of inconvenience to the patient, then give him an option whether he wants to go ahead or not. (9: physician working in pain clinic)

In this case, it was stated "a few weeks". This can mean months, years. I don't know how long. If it is very long, then we can give the treatment ... For instance, if the patient will live a few more years, then we can give the treatment. If it's only a matter of two to four weeks, then there is no use. (15: nurse working in palliative-care unit)

A home-care nurse and a home-care physician told it is important to consider whether there are family members or relatives who are willing and able to care for the terminal patient.

You also should wonder whether the family will be able to help him. (10: home-care nurse)

In addition to these arguments, the interviewees referred to the fact that many Indian families cannot afford expensive curative or life-sustaining treatment. The respondents argued that expenses for the medical treatment of one family member can financially ruin a whole 
family. According to the participants, this financial aspect should be taken into consideration while deciding about the initiation of curative or life-sustaining treatment.

There're certain rich patients who have a lot of money to spare. They will not listen to your advice. They'll go ahead. But if a poor family needs two lakhs more to have a treatment which will prolong life with a few weeks, this will probably have a damaging effect on the family which is left behind. (14: home-care physician)

The patients who come to us have already spent a lot of money. They underwent chemotherapy, surgery. And the medicine is also not too cheap. The patient becomes rather poor. If they have only a little bit of money, they shouldn't undergo a treatment which will prolong life with just two or three weeks. (18: nurse working in palliativecare unit)

Some interviewees added that it is in fact impossible to use objective criteria while deciding about the administration of curative or life-sustaining treatment because sometimes patients can be so much attached to life, or have a particular goal in life, so that they want to live by all means.

Once it comes to the death, every day becomes very precious for you. ... Even if you are able to get a month, or two weeks, this becomes very important for them. (4: homecare physician)

If the patient wants to live, then we definitely have to administer the treatment (26: home-care nurse).

Suppose, if he has to do some very important work in his life, in those few weeks, and if we can grant him those few days, then it's important to get that chemotherapy. It all depends on the patient, on what he wants. ... If a patient's daughter will get married within a period of one to three weeks, I think in that case we can give this chemotherapy although it has got many negative side-effects. (27: physician working in pain clinic and palliative-care unit)

Two physicians argued that the resources in Indian hospitals are limited. Hospital beds, life-sustaining equipment and curative treatment cannot be provided to all patients who 
want or need it. Therefore, difficult ethical choices have to be made about which patients will receive curative or life-sustaining treatment and which ones will not.

If a terminally ill patient occupies a bed in our hospital for, let's say, two months, then it would be better if a patient who can get cured or a young patient gets the treatment. (12: physician working in pain clinic and palliative-care unit)

Thus, the palliative-care physicians and nurses were very much aware that the decisions about curative or life-sustaining treatments in terminal patients can be very complex. Therefore, they considered it their task to provide correct and clear medical information about the treatment options to the patients and their family members, so that the patients and their relatives can make informed decisions.

We have to tell the outcome [of the treatment]: what will happen and what are the sideeffects. We have to explain. Then the choice you have to leave to them. We have to respect their decision. (1: home-care nurse)

I should only give all the options available and all the effects inside the patient. It is for them to decide, not me. (11: physician working in pain clinic and palliative-care unit)

The physicians and nurses agreed that the final decision about curative or lifesustaining treatment has to be taken by the patient and his or her family members. The treating physicians and nurses play an advisory role in the decision-making process.

Here we have to respect the decision of the patient and his relatives. It is not so that we can just take our own decision (15: nurse working in palliative-care unit).

This absolutely depends upon the patient and the patient's relative. What they want, we do. We don't say no to any type of treatment. (5: home-care nurse)

The interviewees saw the family and the patient as a unity. The physicians and nurses were of the opinion that ideally the patient and his family members jointly decide about the administration of curative or life-sustaining treatment. They argued that in India the family, rather than the individual is put at the centre when important decisions are made. 
Normally the social network here is very good. The whole family lives together. (3: home-care physician)

This does not mean that the physicians and nurses did not value the opinion of the individual patient. On the contrary, the interviewees thought that without the patient's permission no treatment can be administered.

You have to respect the patient's choice. You have to give them their choice. We have to explain them what all the benefits and side-effects are. We have to explain what will happen if the patient undergoes the treatment. Then, you have to give them their choice. (1: home-care nurse)

The opinion of the patient is most important. (7: physician working in pain clinic and palliative-care unit)

The patient's decision should be respected, whether he wants to prolong his life or wants symptom relief. ... His will should be respected. (13: physician working in pain clinic and palliative-care unit)

If we are truly concerned about the patient, then we give the treatment if the patient wants it. Otherwise we don't give it. (18: nurse working in palliative-care unit)

Yet, the interviewees were also aware that some patients are incapable of making important decisions regarding curative or life-sustaining treatment, for instance when the patient is very young, not in a good mental condition or uneducated. In that case, a close relative should decide which treatment has to be administered to the patient.

Sometimes a patient is unable to understand anything and there's an elder son who takes all the responsibility. So, as a physician, my duty is to explain everything to the elder son. And finally he is the one who decides about the treatment. (4: home-care physician)

I'll do what the patient says, provided that the patient is mentally sound and not a minor. (7: physician working in pain clinic and palliative-care unit)

The physicians and nurses admitted that sometimes the relatives want to decide about a treatment without informing the patient, although the patient is in a good mental condition. 
In such cases, the family often tries to hide the diagnosis for the patient, because they fear that the patient will not be able to cope with the illness once the diagnosis is revealed.

If the patient is a senior citizen, like their father or an elderly female, then they don't even clearly inform him or her about the diagnosis, fearing that it may upset the patient. And they only take the decision. The family, the relatives only take the decisions. (9: physician working in pain clinic)

The interviewees thought it is not right to hide a diagnosis from a competent patient. They wanted the patients to be aware of their diagnosis and understand it, so that the patients are mentally prepared and can voice their opinion regarding treatment options.

I insist that the patient should be aware of his diagnosis. ... Mentally the patient is to be prepared. It should not come as a shock to her or him. So I always tell the family that in whatever way they can explain, they should tell the patient. (9: physician working in pain clinic)

First we have to know the patient's concerns, because that is always required. Therefore, we mentally prepare the patient. What does he want? Does he have so much money that he can afford it? He may also suffer from the treatment. It is not absolutely sure he'll benefit from the treatment. So if he does not want the treatment, we don't administer it. (18: nurse working in palliative-care unit)

\section{Attitudes to Non-treatment Decisions}

The physicians and nurses were requested to give their opinion on a case about an unconscious patient who is in an irreversible coma and is artificially kept alive with a ventilator and artificial nutrition and/or hydration. The interviewees were asked whether the devices should be switched off to allow the patient to die. The palliative-care nurses and physicians who were interviewed were generally not directly involved in decisions regarding withdrawal of treatment in comatose patients. Some participants told that they found it hard to comment on the case since they did not have first-hand experience with this kind of decisions. 
We don't see patients in that stage because we are caring for palliative-care patients. In the home setting we do not have any patient like that. (2: home-care nurse)

This question is not applicable to us because we don't have a ventilator or anything like that on our palliative-care ward. (18: nurse working in palliative-care unit)

Yet, the palliative-care physicians and nurses were not at all indifferent to the fate of comatose patients who are undergoing intensive life-sustaining treatment, and most believed they could give meaningful advice in such a case. Out of the 27 participants, 8 essentially did not consider the withdrawal of the life-sustaining treatment an acceptable option in the contemporary Indian context. While reflecting upon the case, the interviewees did not only take the physical well-being of the patient into consideration, but also referred to the larger socio-economical and legal context of the decision.

The physicians and nurses mentioned basically three arguments in favour of withdrawing the life-sustaining devices. The first reason mentioned in favour of withdrawal of the life-sustaining devices was the futility of life-sustaining treatment for the patient in the hypothetical case. Almost all participants who approved of withdrawing the devices gave this argument. The physicians and nurses stated that the patient's quality of life is very low.

Life is not precious in this way. Everything is artificial. He's on a ventilator. And he is in an irreversible coma. (4: home-care physician)

A few participants even stated that in fact the terminal patient in the case is already death. In their opinion no meaningful life is preserved by administering the life-sustaining treatment.

This is not real life. (10: home-care nurse)

The patient does not die because we stop [the treatment]. But in a way with this ventilator we are only prolonging life. We are preserving a dead body. (22: hospice nurse)

The patient is already death, basically. He has been kept alive with these [life-sustaining devices]. (4: home-care physician) 
According to the palliative-care physicians and nurses the life-sustaining treatment in no way improves the patient's condition which is irreversible.

Putting a patient who is irreversibly brain death on a ventilator is just making money. This is unprofessional. (14: home-care physician)

There is no point in continuing such treatment in such patient, because he is in an irreversible coma. (25: hospice physician)

For these participants, the patient in the case does not benefit from the life-sustaining treatment. On the contrary, according to the participants who advocated withdrawal of lifesustaining treatment the treatment just prolongs the patient's suffering.

There is no use [of such treatment]. How long will we prolong suffering? (24: hospice nurse)

Actually this patient is dying. If we give ventilator support this will only cause more struggle. (26: home-care nurse)

Instead of needlessly prolonging the patient's suffering, these interviewees argued that lifesustaining devices should be removed and the caregivers should take care of the patient so that he or she can die peacefully.

We can withdraw the life-sustaining devices according to me. After withdrawing all that, just a little bit of time is left. He should be kept comfortable. (20: home-care nurse)

The second reason which was mentioned in the interviews in favour of withdrawing the devices is the observation that such devices are expensive and prolonged use of such devices can financially ruin a family, while the patient himself will not really benefit from the treatment.

It won't be of any benefit. It will only drain the financial resources and finances of the patient's relative. (27: physician working in pain clinic and palliative-care unit) 
The third reason in favour of withdrawing the devices was that the use of lifesustaining devices for a comatose patient who will never wake up, is a waste of the scarce medical resources in India. The same devices which are used to sustain the life of a patient who will die without quality of life, could also be used to rescue the life of another patient who may have more chances to live a meaningful life afterwards.

The truth is that it would be better to use this equipment for a patient who can recover. (18: nurse working in palliative-care unit)

It should be used for another patient who can be cured, instead of using it for that patient who can't be cured. (3: home-care physician)

Most of the participants who found withdrawal of life-sustaining treatment ethically acceptable were of the opinion that decisions to withdraw such treatment should be taken by the patient's relatives after consultation with the treating physician. According to these interviewees, the physician can advise the relatives, but the relatives take the final decision regarding the continuation or withdrawal of the life-sustaining treatment.

This patient's family has to decide, because the patient is not in a position to decide. (3: home-care physician)

It has to be the family's decision. The physician can only explain. (4: home-care physician)

The patient's relative should take the decision. (1: home-care nurse)

One Home-care nurse (1) added that normally the relatives of an unconscious patient should decide about continuation or withdrawal of treatment, unless the patient has expressed his or her wishes regarding the withdrawal or continuation of treatment before he or she became unconscious. In that case, the patient's wishes should be followed.

Two physicians were of the opinion that a decision regarding the continuation or withdrawal of treatment should be taken jointly by the treating physician and the patient's 
relatives. Both parties should reach a consensus which is in the best interest of the patient. If the physician and relatives disagree, the court may have to decide.

It should be decided by both family and treating physician. ... If there's conflict then it may be decided by the court of law, because these things are done in the best interest of the patient. (13: physician working in palliative-care unit and pain clinic)

Only a few participants were of the opinion that the physician should unilaterally decide to withdraw life-sustaining devices when a patient is in an irreversible coma. A physician working in a palliative-care unit and a pain clinic (12) explained that according to him the patients' relatives should not decide about withdrawal of life-sustaining treatment, because relatives will never be able to take such a decision. If after deciding the physician explains the reasons for the withdrawal of the life-sustaining devices to the relatives, they will finally consent to his or her decision. According to another physician, who works in a pain clinic (6), the physician should ideally decide in consultation with the patients' relatives. Yet, according to this participant, sometimes when the patient's relatives are poor and uneducated, they may not understand the patient's condition. In that situation, the physician may have to decide unilaterally about the withdrawal of life-sustaining treatments.

In the interviews, the participants offered three main arguments against withdrawal of life-sustaining treatment in the present Indian context. A few respondents likened the withdrawal of life-sustaining treatment, and particularly withdrawal of a ventilator, to killing. Therefore, they argued that withdrawal of life-sustaining treatment is ethically objectionable.

You can't kill and strain your hands in blood. ... Either removing the ventilator or giving a lethal injection: it is one and the same thing. (11: physician working in palliative-care unit and pain clinic)

The physician who gave the quoted argument later in the interview explained that humans do not have the right to decide about the moment of death because this right only belongs to God. Therefore a physician should not withdraw life-sustaining treatment. 
I think it is always God who decides everything. That is why I think doctors should not decide about life and death of the patient.

Two participants were against withdrawal of life-sustaining treatment because, in their opinion, a physician can never predict the outcome of a disease with full certainty. They argued that there remains a chance that a comatose patient will wake up.

There is always hope. ... Someone may someday come out of a ventilator. You can't say. (11: physician working in palliative-care unit and pain clinic)

Suppose that in my family there would be somebody like this, in that case I want that the ventilator should be on, because maybe some miracle will happen or he or she will come out of coma. (3: home-care physician)

Most participants who were against the withdrawal of life-sustaining treatment held this opinion because at present in India there is no legal framework for the withdrawal of such treatment.

Once we have put him [on the ventilator] how can we take him off? Why have we put him then, because still legally we cannot wean him off? (15: nurse working in palliative-care unit)

We do not practice it here ... because it is not allowed in our country. We cannot switch off the respirator and stop the artificial nutrition and hydration and other things. (7: physician working in palliative-care unit and pain clinic)

Half of the participants who mentioned the lack of a legal framework for withdrawal of life-sustaining treatment as an argument against this practice, nevertheless considered withdrawal of the life-sustaining devices in the hypothetical case acceptable from an ethical point of view. If withdrawal of life-sustaining treatment were legal in India, they would support the practice in the case of a patient who is in an irreversible coma and who is artificially kept alive. 
The participants disagreed whether Indian law actually permits withdrawal of lifesustaining treatment. One physician (19) and one nurse (18) admitted they did not know whether withdrawal of life-sustaining treatment is allowed as per Indian law.

I don't know whether it is legal or not, but it happens all the time. (19: home-care physician)

A few participants were of the opinion that Indian law explicitly forbids any medical act which may hasten death. As a consequence, these interviewees thought that the withdrawal of life-sustaining treatment is against Indian law.

In all classes I have attended I have heard that euthanasia is not allowed. Any kind of euthanasia is not allowed in India. (15: nurse working in palliative-care unit)

This is not right. It is not legal. According to the law this is not right. (17: nurse working in palliative-care unit)

A physician working in a palliative-care unit and pain clinic (11), argued that Indian law actually forbids killing. Since this participant considered withdrawing of life-sustaining treatment ethically equal to killing, he argued that withdrawal of life-sustaining treatment is forbidden as per Indian law.

However, most participants who commented upon the issue of the legality of withdrawal of life-sustaining treatment in India thought that in India there is no concrete law regulating these issues. Some participants commented that in case of conflicts, Indian courts could grant or refuse permission to withdraw life-sustaining treatment.

It has not been legalised in India. No such rule is applicable. But the court can give an order depending upon the situation. (12: physician working in palliative-care unit and pain clinic)

A few other interviewees who were also of the opinion that there is no concrete law regulating withdrawal of life-sustaining treatment in India told that life-sustaining treatment 
may nevertheless be withdrawn if the relatives provided a written and signed document stating that they wanted the treatment to be withdrawn, or signed a LAMA-form (Leave Against Medical Advice) and the withdrawal of the treatment was done at home. A physician (9) argued that another possibility to withdraw life-sustaining treatment with the relatives' consent without risking legal hassles is to withdraw only those life-sustaining treatments after whose withdrawal the patient will not die immediately, e.g. artificial nutrition.

Since withdrawal of treatment is a complex issue both from the legal and the ethical perspective, some interviewees concluded that a physician should reflect well before initiating life-sustaining treatment as it may be very difficult to withdraw that treatment at a later stage.

If we knew beforehand that the patient will not benefit from the treatment, then we should not have administered it. (15: nurse working in palliative-care unit)

In case of an incurable disease or irreversible coma you should not put the patient on the ventilator. Why you're giving the treatment when you'll have to withdraw it? Take a very wise decision at that moment. (4: home-care physician)

\section{Attitudes to Refusal of Treatment}

After hearing the case about a hypothetical cancer patient who refuses a life-saving curative treatment which he or she can afford, a few interviewees commented that it is very unlikely that such a patient will refuse a curative treatment.

I have hardly seen any patients like that. Everyone wants to get treatment. (20: homecare nurse)

Yet, other respondents considered it conceivable that a cancer patient would refuse a possibly life-saving curative treatment. These interviewees tried to understand the reasons behind the refusal. They considered it their task to explain to the patient and his or her relatives the benefits of the treatments and the consequences of the refusal. Yet, finally the decision about the treatment was left to the patient. 
The physicians and nurses mentioned several contextual reasons why a patient could refuse a life-saving curative treatment. According to the interviewees some patients may dread side-effects of certain therapies more than death. Patients may also fear that the treatment will leave them disfigured.

Why does he want to die soon? ... Is he refusing because he knows about the toxic sideeffects of the treatment? (14: home-care physician)

Sometimes they have to remove one breast. So the patient is disfigured. She may think: “How will I meet people without one breast?" (18: nurse working in palliative-care unit) Even if the patient can afford the treatment, he or she may still prefer not to spend his or her hard-earned money for the cancer treatment.

But even then, he may have put that money for something else. (3: home-care physician)

Sometimes patients may also refuse a curative treatment because they have more faith in alternative therapies, like homoeopathy and ayurvedic medicine. Providers of alternative medicine often guarantee and promise absolute cure. This kind of promises may attract patients who have lost faith in Western-style medicine.

Some of these alternative-medicine people say: "You will get cured!" They promise that. But in medicine we don't promise. At least we won't promise that you'll be cured. So the patients think that that is better. (3: home-care physician)

The palliative-care nurses and physicians unanimously agreed that a patient has the right to refuse a life-saving curative treatment. A treatment can never be forced upon a patient without the patient's consent.

Since he has money and he knows that his cancer will get cured, he should not refuse the treatment. But, everything depends on the patient. (15: nurse working in palliativecare unit) 
If the patient does not want to take a treatment, how can one force him to accept or take the treatment? (8: physician working in palliative-care unit and pain clinic)

The patient's consent is most important for any treatment. When we want to take the patient for surgery or chemo-therapy, or even any investigation, like a CT-scan, if the patient is not giving consent, then naturally one cannot go ahead with the treatment. (9: physician working in pain clinic)

The participants considered it the task of the treating nurses and physicians to explain to the patient and his or her relatives how the treatment can save the patient, and to warn them against the dire consequences of not undergoing the curative treatment. Yet, in the end the patient has to decide and the physicians and nurses must accept the patient's decision.

We have to make the patient understand. The patient has the right [to refuse the treatment]. But at the same time it is the patient's right to get cured, if a treatment is there. (22: hospice nurse)

In such case, I will explain him that with this medicine we can cure his illness. Then, if he is not convinced, I will talk to his relatives. I'll explain to them. Then I'll talk to him again. If the patient still doesn't agree, I'll have to respect the patient's wish and I will not administer the treatment. (7: physician working in palliative-care unit and pain clinic)

We can only make him understand. We can only interact with the patient again and again and again. And we can only make him understand that the treatment is good for him. But if he bluntly refuses the treatment, we cannot force it. (8: physician working in palliative-care unit and pain clinic)

\section{Discussion}

Withholding a curative or life-sustaining treatment which may prolong a terminal cancer patient's life with a few weeks but also has severe side-effects was generally considered acceptable by the palliative-care physicians and nurses. There was more disagreement among the participants regarding withdrawing life-sustaining treatments in a patient who is in an 
irreversible coma. Eight out of 27 participants did not find withdrawal of life-sustaining therapy an acceptable option in the present Indian context. Yet, overall a majority found withdrawal of treatment acceptable. The interviewees agreed that a patient has the right to refuse a curative treatment.

Concern for the Whole Patient and for the Larger Impact of the Treatment Decision

In the arguments of the physicians and nurses, the concern for the whole patient, and for other people who may be affected by the decision to start or continue the curative or life-sustaining treatment was prominent. While reflecting upon the ethical acceptability of withholding or withdrawal of curative or life-sustaining treatment, the physicians and nurses did not restrict their thoughts to the physical aspects of the patient's disease. Earlier studies have shown that for patients and their relatives at the end of life treatment of physical pain is important, but also psychosocial issues and spiritual needs are areas of concern for the patients and their relatives (Singer et al., 1999; Steinhauser et al., 2000). The palliative-care physicians and nurses were very much aware of that fact.

This explains why the interviewees did not consider decisions about withholding or withdrawing of curative or life-prolonging treatment a matter strictly between the patient and the medical team. The interviewees wanted the family to be involved in the decision-making process because the palliative-care nurses and physicians were aware that a decision to start, continue, withhold or withdraw a curative or life-sustaining treatment can have far-reaching physical, emotional, psychological and social consequences not only for the patient, but also for his or her family. Prolonged administration of expensive treatment can, for instance, financially drain a family since health insurance is uncommon in India (Mani, 2003). This does not mean that the voice of the individual patient will not be heard in the decision-making process. Yet, since the treatment decision is seen as affecting the whole family, also the 
opinions of the other family members and especially the opinion of the head of the family are considered (Chattopadhyay and Simon, 2008). Sureshkumar and Rajagopal observed that Indian cancer patients generally are not having any problems with the involvement of family members and carers when treatment options are being discussed. Often patients are even unwilling to take part in the decision-making process (Sureshkumar and Rajagopal, 1996).

The palliative-care physicians and nurses were also aware that in India a decision to continue or initiate a curative or life-sustaining treatment may determine the fate of other patients who are also in need of the same treatment. Scarcity of resources is a huge problem in Indian health care. Administering a treatment to one particular patient, will sometimes imply that these drugs or medical equipment are not available for the treatment of another needy patient (Chattopadhyay and Simon, 2008). Physicians and nurses working in neonatal care in India face similar problems. Many families cannot afford the neonatal care their newborn child requires, and the hospitals do not have sufficient funds to provide free treatment to all these newborns (Miljeteig and Norheim, 2006; Miljeteig et al., 2009). Moreover, in most Indian hospitals life-sustaining equipment, like ventilators, is scarce. Thus, providing lifesustaining treatment to one child, sometimes implies that another child will die because the equipment is not available to him or her (Miljeteig and Norheim, 2006).

\section{Religious Arguments}

On the basis of earlier research, a more profound influence of religion on attitudes to withholding and withdrawal of curative or life-sustaining treatment could have been expected. Christakis and Asch observed that internists who are Catholic or Jewish are less likely to be willing to withdraw life support (Christakis and Asch, 1995). In the EURELD study, it was found that religion and world view determine attitudes to non-treatment decisions. Religiously committed physicians were less likely to agree that a physician should comply with a patient's 
request to withhold or withdraw life-sustaining treatment (Miccinesi et al., 2005). In a study in the Netherlands, $28 \%$ of physicians and $21 \%$ of nurses stated to have religious beliefs that do influence their decision making regarding forgoing artificial nutrition and hydration (Rurup et al., 2006).

Two theoretical studies dealing with Hindu attitudes to withholding and withdrawal of treatment are more directly relevant to the Indian context. Firth linked possible approval of withdrawal of treatment by Hindus with the ideas of religious voluntary death and religious suicide in Hinduism. In Hinduism, it is sometimes argued that spiritually advanced persons can derive merit from fasting to death or commit suicide in the pursuit of higher religious goals. On this basis, Firth argued that withdrawal and withholding of treatment could be acceptable to Hindus (Firth, 2005). Gatrad et al. argued that for Hindus withdrawal of futile treatments is generally acceptable because in Hinduism death is seen as a consequence of bad deeds done in the past (karma), and therefore most Hindus will accept illness and death in a fatalistic way (Gatrad et al., 2003). The conclusions of Gatrad et al. may have been simplistic. Some Hindus are indeed of the opinion that suffering and death are a consequence of karma. Yet, such theories may not always make acceptance of death easier. On the contrary, some Hindus may be convinced that their time has not yet come, and that therefore all possible lifeprolonging treatments should be applied. Moreover, none of the arguments offered by Firth and Gatrad were mentioned by the interviewees in our research.

In the interviews, only one religious argument was mentioned regarding withholding or withdrawal of curative or life-sustaining treatment. This argument was put forward in the context of withdrawal of life-sustaining treatment and had to do with the idea that only God has the right to decide about life and death. In order to adhere to this argument, a physician or nurse should not only be religious, but also be convinced that by withdrawing a curative or life-sustaining treatment a physician actually decides about life and death. Since only very 
few participants likened withdrawal of life-sustaining treatment to killing, it is clear that most participants did not think the physician decides about life and death in this case. Most interviewees thought that withdrawing the life-prolonging treatment in the hypothetical case is not the cause of the patient's death. The treatment is just futile and prolongs suffering. Since in their opinion the physician does not decide about life and death in the hypothetical case, the argument that only God has the right to decide about life and death, is not applicable.

\section{Advisory Role of the Palliative-care Team}

Although the physicians and nurses had their own ideas on which treatment option is better in particular cases, they argued that physicians and nurses should not impose their views on the patients or their relatives. According to the interviewees, in the end it is the patients and their relatives who should decide about the treatment. The interviewees were convinced that in the decision-making process the palliative-care physicians and nurses can play an important advisory role. This became very clear in the interviewees' reactions to the case of the refusal of treatment.

When sufficient means are available to provide a treatment, it can happen that a patient is unwilling or does not undertake any effort to undergo a treatment, even if the treatment could cure him or her. Mohanti et al. observed that defaulting of treatment is a major problem in Indian cancer care. In their study of cancer patients in a regional cancer centre in New Delhi, 38\% of patients for whom curative treatment had been planned, and $46 \%$ of patients who were supposed to undergo palliative treatment did not comply with the treatment at the studied cancer centre (Mohanti et al., 2007). Gupta et al. identified six possible causes of defaulting of treatment by Indian cancer patients: poor doctor/patient rapport, inadequate communication between doctor and patient about the disease and its treatment, unavailability of a "no show" defaulters' programme and case managers, patient's 
economic constraints, additional inconveniences because of referrals and consultation in a large multispecialty state-run hospital, and the patient's low education level and poor understanding of the disease and its treatment (Gupta et al., 2007).

Lack of understanding of the disease and its treatment may also nourish unrealistic expectations and false hopes regarding chances of survival. Driven by these hopes patients in India will often try all kinds of treatments (Mani, 2003), including treatments of different alternative systems of medicine. Sureshkumar and Rajagopal found that one third of the patients who presented for palliative treatment at a palliative-care unit in the South-Indian state of Kerala were also undergoing alternative treatments which aimed at cure (Sureshkumar and Rajagopal, 1996). Providers of alternative treatment may further stimulate hopes regarding cure and encourage mistrust towards Western-style medicine. In this way, patients may finally decide to forgo treatments which are required according to modern medicine (Mani, 2003).

The interviewed palliative-care physicians and nurses were aware of various reasons why patients do not comply with curative treatment or refuse treatment. The participants discussed these reasons in the interviews. The interviewees did not blame the patient for defaulting the treatment, but instead stressed the importance of proper guidance. According to the palliative-care physicians and nurses the prognosis and the treatment should be adequately explained to the patient and his or her relatives, so that the patient and his or her family can take a proper informed decision. The palliative-care physicians and nurses agreed that a patient has the right to refuse life-saving curative treatment and that a treatment cannot be forced upon the patient.

Yousuf et al. obtained very different results in Srinagar in the Indian state of Jammu and Kashmir. They observed that $83 \%$ of physicians considered the administration of a lifesaving intervention acceptable even when the patient has refused informed consent (Yousuf et 
al., 2007). Since Yousuf et al. do not provide much demographic information about the respondents, it is difficult to explain why most surveyed physicians in Srinagar found the administration of curative treatment without the patient's consent acceptable, while the palliative-care physicians and nurses in New Delhi did not agree to such practice. Since the survey of Yousuf et al. was carried out in Srinagar, a city with a predominantly Muslim population (Office of the Registrar General \& Census Commissioner India, 2009), it is possible that the Muslim context made the physicians in that study to be more willing to administer a life-saving treatment even when the patient refused informed consent. Many Islamic scholars would agree that curative or life-sustaining treatment ought not to be forgone (al-Mousawi et al., 1997; Sachedina, 2005).

It is also possible that the palliative-care nurses and physicians who are working in the capital of India have been more exposed to Western biomedical ethics, in which informed consent is a central aspect. Moreover, throughout their training and experience as palliativecare nurses and physicians, the interviewees may have learned that physical, psychosocial, economical and spiritual aspects of the illness have to be taken into consideration while treating a patient. In this way, the palliative-care nurses and physicians may have come to understand that a nurse or physician's perception of a patient's disease is always partial, and that finally only the patient and his or her near ones can decide about the meaningfulness of a treatment. While the ethical opinions of the physicians in Srinagar seem to be prompted by a paternalistic attitude, the arguments of the Indian palliative-care nurses and physicians are characterised by patient centeredness. This contrast shows that also within Indian health-care there exist various views regarding the position of physicians and nurses in the medical decision-making process. 
Shortcomings of the Study

In this study we assessed attitudes of nurses and physicians working in palliative care in New Delhi. Although the backgrounds of the physicians and nurses who were included in the study were diverse, it is not clear to what extent our observations can be generalised to palliativecare physicians and nurses working in other Indian states.

Only physicians and nurses who knew English or Hindi sufficiently well to be interviewed were included in the study. In palliative care in New Delhi, there are also few nurses of South-Indian origin who are only fluent in their South-Indian mother tongue (most often Malayalam) and have only a basic knowledge of Hindi or English. These nurses were not interviewed and it is unclear whether their views regarding forgoing curative or lifesustaining treatment differ from those of their colleagues who do easily speak and understand Hindi or English.

In this study we also did not explicitly attempt to compare the attitudes and opinions of physicians and nurses, or assess the differences in opinion between physicians and nurses working in different types of palliative care. It seems, however, that the opinions of these different groups of participants are largely complementary, rather than contrastive.

\section{Conclusion}

Withholding a curative or life-sustaining treatment which may prolong life with a few weeks, but also has many side-effects, is an acceptable medical practice according to the palliativecare physicians and nurses. The majority of the physicians and nurses agree that lifesustaining treatment can be withdrawn in a comatose patient who will never wake up. If a patient refuses a curative treatment, the physicians and nurses are of the opinion that the will of the patient should be respected. While reflecting upon these ethical issues the physicians and nurses think beyond the physical aspects of the disease, and take the complex psycho- 
social and economic context into consideration. The nurses and physicians are convinced they can play a crucial advisory role in the decision-making process.

We undertook a qualitative study in one Indian metropolitan city through which we aimed at gaining insight into the attitudes of palliative-care physicians and nurses towards the initiation or continuation of curative or life-sustaining treatment, non-treatment decisions, and refusal of treatment in advanced disease. On the basis of this explorative study larger studies regarding these issues could be undertaken in India. Through such studies researchers could try to assess whether there are differences in attitudes between palliative-care physicians and nurses in different Indian states, and diverging palliative-care contexts.

\section{References}

al-Mousawi, M., Hamed, T. et al.: 1997, 'Views of Muslim scholars on organ donation and brain death'. Transplant proceedings 29 (8), 3217.

Balakrishnan, S. and Mani, R.K.: 2005, 'The constitutional and legal provisions in Indian law for limiting life support'. Indian J Crit Care Med 9 (2), 108-114.

Bosshard, G., Nilstun, T. et al.: 2005, 'Forgoing treatment at the end of life in 6 European countries'. Arch Intern Med 165 (4), 401-407.

Broeckaert, B.: 2008, 'Treatment decisions at the end of life: A conceptual framework', in: S. Payne, J. Seymour and C. Ingleton (eds.), Palliative care nursing. Principles and evidence for practice. Birkshire: Open University Press: 402-421.

Broeckaert, B.: 2009a, 'Euthanasia and physician assisted suicide', in: D. Walsh (ed.), Palliative medicine. Philadelphia: Elsevier: 110-115.

Broeckaert, B.: 2009b, 'Treatment decisions in advanced disease: A conceptual framework'. Indian J Palliat Care 15 (1), 30-36.

Broeckaert, B. and Flemish Palliative Care Federation: 2006, 'End of life decisions - A conceptual framework'. $\quad$ Retrieved 16 September 2008, from http://www.palliatief.be/.

Chattopadhyay, S. and Simon, A.: 2008, 'East meets West: cross-cultural perspective in endof-life decision making from Indian and German viewpoints'. Med Health Care Philos $11(2), 165-174$.

Christakis, N.A. and Asch, D.A.: 1995, 'Physician characteristics associated with decisions to withdraw life support'. Am J Public Health 85 (3), 367-372.

Firth, S.: 2005, 'End-of-life: a Hindu view'. Lancet 366 (9486), 682-686.

Gatrad, R., Choudhury, P.P. et al.: 2003, 'Palliative care for Hindus'. Int J Palliat Nurs 9 (10), 442-448.

Glaser, B.G. and Strauss, A.L.: 1974, The discovery of grounded theory. Strategies for qualitative research. Chicago: Aldine Publishing Company. 
Gupta, D., Bhatnagar, S. et al.: 2007, 'Defaulting oncology patient in a multispecialty staterun hospital in India'. Am J Hosp Palliat Care 24 (1), 59-62.

International Observatory on End of Life Care: 2007, 'India country report'. Retrieved 30 November 2007, from http://www.eolcobservatory.net/global_analysis/pdf/india_country_report.pdf.

Kapadia, F., Singh, M. et al.: 2005, 'Limitation and withdrawal of intensive therapy at the end of life: practices in intensive care units in Mumbai, India'. Crit Care Med 33 (6), $1272-$ 1275 .

Kuhse, H., Singer, P. et al.: 1997, 'End-of-life decisions in Australian medical practice'. Med J Aust 166 (4), 191-196.

Mani, R.K.: 2003, 'Limitation of life support in the ICU: Ethical issues relating to end of life care'. Indian J Crit Care Med 7 (2), 112-117.

McDermott, E., Selman, L. et al.: 2008, 'Hospice and palliative care development in India: a multi-method review of services and experiences'. J Pain Symptom Manage 35 (6), 583-593.

Miccinesi, G., Fischer, S. et al.: 2005, 'Physicians' attitudes towards end-of-life decisions: a comparison between seven countries'. Soc Sci Med 60 (9), 1961-1974.

Miljeteig, I. and Norheim, O.F.: 2006, 'My job is to keep him alive, but what about his brother and sister? How Indian doctors experience ethical dilemmas in neonatal medicine'. Developing World Bioeth 6 (1), 23-32.

Miljeteig, I., Sayeed, S.A. et al.: 2009, 'Impact of ethics and economics on end-of-life decisions in an Indian neonatal unit'. Pediatrics 124 (2), e322-328.

Mohanti, B.K., Nachiappan, P. et al.: 2007, 'Analysis of 2167 head and neck cancer patients' management, treatment compliance and outcomes from a regional cancer centre, Delhi, India'. J Laryngol Otol 121 (1), 49-56.

Office of the Registrar General \& Census Commissioner India: 2009, 'Website on Census of India'. Retrieved 20 October 2009, from http://www.censusindia.gov.in/.

Rajagopal, M.R. and Palat, G.: 2002, 'Kerala, India: status of cancer pain relief and palliative care'. J Pain Symptom Manage 24 (2), 191-193.

Rurup, M.L., Onwuteaka-Philipsen, B.D. et al.: 2006, 'Attitudes of physicians, nurses and relatives towards end-of-life decisions concerning nursing home patients with dementia'. Patient Educ Couns 61 (3), 372-380.

Sachedina, A.: 2005, 'End-of-life: the Islamic view'. Lancet 366, 774-779.

Seale, C.: 2006, 'National survey of end-of-life decisions made by UK medical practitioners'. Palliat Med 20 (1), 3-10.

Seamark, D., Ajithakumari, K. et al.: 2000, 'Palliative care in India'. J R Soc Med 93 (6), 292295.

Shanmugasundaram, S., Chapman, Y. et al.: 2006, 'Development of palliative care in India: an overview'. Int J Nurs Pract 12 (4), 241-246.

Singer, P.A., Martin, D.K. et al.: 1999, 'Quality end-of-life care: patients' perspectives'. Jama 281 (2), 163-168.

Steinhauser, K.E., Christakis, N.A. et al.: 2000, 'Factors considered important at the end of life by patients, family, physicians, and other care providers'. Jama 284 (19), 24762483.

Strauss, A.L. and Corbin, J.: 1998, Basics of qualitative research. Techniques and procedures for developing Grounded Theory. Thousand Oaks - London - Delhi: Sage Publications.

Sureshkumar, K. and Rajagopal, M.R.: 1996, 'Palliative care in Kerala. Problems at presentation in 440 patients with advanced cancer in a south Indian state'. Palliat Med 10 (4), 293-298. 
World Health Organisation Country Office for India: 2006, 'WHO Country Cooperation Strategy 2006-2011: India'. Retrieved 22 May 2010, from http://www.who.int/countryfocus/cooperation_strategy/ccs_ind_en.pdf.

Yousuf, R.M., Fauzi, A.R. et al.: 2007, 'Awareness, knowledge and attitude toward informed consent among doctors in two different cultures in Asia: a cross-sectional comparative study in Malaysia and Kashmir, India'. Singapore Med J 48 (6), 559-565. 